\title{
ANA Ma MARCOS DEL CANO: EL DERECHO A LA SALUD DESDE EL PUNTO DE VISTA ÉTICO-JURÍDICO ${ }^{1}$
}

\section{THE RIGHT TO HEALTH: ETHICAL AND LEGAL PERSPECTIVES}

RESUMEN: La actual coyuntura económica ha supuesto reformas legislativas que han afectado al núcleo esencial del derecho a la protección a la salud y a sus prestaciones. Este cambio normativo nos obliga a reflexionar sobre el alcance que pueden tener las medidas de sostenibilidad económica cuando se produce una negación de los derechos individuales que fundamentan el Estado social y democrático de Derecho. El objetivo de este artículo es justificar que el derecho a la protección a la salud, como derecho social, debe tener alcance universal. Por tal motivo, debe configurarse como un auténtico derecho fundamental, dada su vinculación con intereses de máxima relevancia como la vida, la integridad física o moral.

SUMMARY: The current economic situation has led to legislative reforms that have affected the essential core of the right to health protection and benefits. This regulatory change forces us to reflect upon the extent to which the measures of economic sustainability result in the denial of individual rights which are the foundation of the social and democratic rule of law. The aim of this article is to prove that the right to health care should be universal. For this reason, it must be configured as a genuine fundamental right given its linkage with interests of the highest relevance such as life, physical or moral integrity.

PALABRAS-CLAVE: Derecho a la protección de la salud, derechos sociales, derechos fundamentales, atención sanitaria, sostenibilidad económica.

KEYWORDS: Right to health, social rights, fundamental rights, health care, economic sustainability.

\section{PLANTEAMIENTO DE LA CUESTIÓN}

\footnotetext{
${ }^{1}$ Catedrática acreditada de Filosofía del Derecho. Este trabajo está realizado dentro del marco del Proyecto de Investigación DER 2013-4162-R del Ministerio de Economía y competitividad del Gobierno de España, del que la autora es IP.
} 
La actual coyuntura económica ha supuesto reformas legislativas que han afectado al núcleo esencial del derecho a la protección a la salud y a sus prestaciones. En concreto, el Real Decreto-Ley 16/2012 ha supuesto una reforma radical de la normativa sanitaria española. En efecto, desde la aprobación de la Ley 14/1986, de 25 de abril, General de Sanidad la prestación sanitaria tenía carácter universal al establecer como titulares del derecho a los españoles y extranjeros que tuvieran establecida su residencia en el territorio nacional. Dicha norma supuso un cambio decisivo por cuanto vinculó el derecho a la salud y a la asistencia sanitaria a la persona y no a la condición de afiliación y alta en el Sistema de la Seguridad Social. Posteriormente, la Ley Orgánica 4/2000, de 11 de enero, de derechos y libertades de los extranjeros en España suavizó el requisito de la "residencia en el territorio nacional" al exigir tan solo que los extranjeros se encontrasen "inscritos en el padrón del municipio en el que residan habitualmente".

Tras la entrada en vigor de la reforma sanitaria de $2012^{2}$, la titularidad del derecho a la salud deja de ser universal para estar supeditada a la condición de asegurado $\mathrm{y}$, por tanto, sujeta al cumplimiento de ciertos requisitos vinculados a la participación en el mercado laboral. La consecuencia de esta nueva normativa es la exclusión de todas aquellas personas no nacionales en situación administrativa irregular, es decir, a los inmigrantes "sin papeles"3. No obstante, la norma contempla tres excepciones: 1) la atención sanitaria de urgencia "por enfermedad grave o accidente, cualquiera que sea su causa, hasta la situación de alta médica"; 2) la atención sanitaria al "embarazo, parto y postparto"; y 3) los menores de dieciocho años que reciben "asistencia sanitaria en las mismas condiciones que los españoles" (artículo 3 ter Ley 16/2003).

Esta reforma, muy criticada por sectores de la Sanidad y por organizaciones sociales así como académicas ${ }^{4}$, cuestiona la protección y

2 BLASCO LAHOZ, J.F., "Modificaciones en materia de asistencia sanitaria consecuencia del RD-L 26/2012, de 20 de abril", Revista de Información Laboral, núm. 11/2012.

${ }^{3}$ Actualmente, de acuerdo con el Informe del Observatorio Internacional de Médicos del Mundo 2016, el 50,6\% de los pacientes atendidos en Europa por esta organización se encuentran en situación administrativa regular. Un total de 1.255 .600 migrantes presentó una "solicitud de protección internacional" en Europa, más del doble que en 2014, véase http://emn.ie/index.jsp?p=100\&n=105\&a=2435, (consultado el 18 de noviembre de 2016).

${ }^{4}$ En este sentido, el día 16 de mayo de 2012 se publicó una declaración conjunta de 35 organizaciones donde se reclamaba el acceso a la asistencia sanitaria como un derecho humano básico y se oponía frontalmente a la creación de un "sistema de salud paralelo" para los inmigrantes irregulares que debilitará los cimientos básicos de los derechos humanos, el derecho a la igualdad y a la no discriminación. Asimismo, la Sociedad Española de Medicina de Familia y Comunitaria apelaba a principios de ética profesional de los médicos que obligan a mantener una relación de confianza y no abandono con el paciente que debe prevalecer sobre la obligación de cumplimiento de la nueva normativa. De igual manera, se alertaba de los riesgos para la salud pública por la propagación de enfermedades con el consiguiente colapso de las unidades de urgencias. Por su parte, la Organización Médica Colegial recordó la obligación del médico de atender, en todo momento, a los pacientes independientemente de su situación legal (artículo 6 y 21 del Código de Deontología Médica), pudiendo acogerse a la objeción de conciencia (artículo 32.1 del Código de Deontología Médica). 
garantía que el Estado otorga universalmente del derecho a la asistencia sanitaria y provoca que se deba repensar cuál es la naturaleza de ese derecho y el papel del Estado en la protección de la salud de los ciudadanos. Por otro lado, y desde un punto de vista de técnica jurídica, se ha cuestionado también el procedimiento utilizado que ha excluido el debate al Parlamento, utilizando la figura del Decreto-Ley ${ }^{5}$.

De este tenor también fue el Decreto-Ley 20/2012, de 13 de julio, para garantizar la estabilidad presupuestaria y de fomento de la competitividad. La citada norma introdujo importantes modificaciones en la Ley 39/2006, de 14 de diciembre, de Promoción de la Autonomía Personal y Atención a las personas en situación de dependencia (la conocida como Ley de Dependencia ${ }^{6}$ ).

El motivo principal que impulsó ambas reformas, tanto la de la titularidad del derecho a la protección de la salud como del sistema de dependencia fue la situación de crisis económica ${ }^{7}$. Estas medidas, por otro lado, han sido avaladas, si bien por motivos formales y competenciales, por el Tribunal Constitucional tanto en el caso de la modificación de la titularidad del derecho a la protección de la salud, afectando dicha reforma al núcleo esencial del derecho, como en el de los recortes en el ámbito de dependencia.

${ }^{5}$ Desde el estallido de la crisis económica en 2008 y, especialmente, a partir del año 2011 el Gobierno ha incrementado notablemente la utilización de esta técnica legislativa para introducir medidas de reforma en prácticamente todos los sectores del ordenamiento jurídico. La extensión del uso de esta facultad excepcional ha generado, ciertamente, un nuevo cuerpo de doctrina constitucional que analiza hasta qué punto la situación económica del país constituía una situación de "extraordinaria y urgente necesidad". Esta situación dista mucho de la recomendable mesura y excepcionalidad con las que en el Estado de Derecho debe hacerse uso por el poder ejecutivo de esta potestad para dictar normas con rango de ley. Vid. ARANA GARCÍA, E., "Uso y abuso del Decreto-Ley", Revista de Administración Pública, núm. 191, mayo-agosto 2013, p. 365: "(...) la situación económica por la que atraviesa nuestro país está sirviendo de coartada a los ejecutivos central y autonómicos para justificar la existencia de una especie de «estado de excepción» que les ampara para gobernar a base de decretos-leyes. Si todo es urgente, puede que nada lo sea. La emergencia o excepción constitucional no puede convertirse en regla de gobierno (...)".

${ }^{6}$ Uno de los aspectos más llamativos de la reforma es que en el Exposición de Motivos se llegue a decir que "la pervivencia del sistema se debe asegurar, necesariamente, a través de una reducción de las prestaciones y de la cobertura a los dependientes". No se puede aprobar una reforma que pretende asegurar la continuidad sistema de atención a la dependencia al mismo tiempo que se le priva de los medios necesarios para cumplir su objetivo.

7 Por tal motivo, el Real Decreto-Ley 16/2012 hace referencia a un concepto económico ("sostenibilidad del Sistema Nacional de Salud") lo que se desarrolla en la Exposición de Motivos cuando afirma que "se ha perdido eficacia en la gestión de los recursos disponibles, lo que se ha traducido en una alta morosidad y en un insostenible déficit en las cuentas públicas sanitarias". En este mismo sentido, en la Exposición de Motivos del Real Decreto 20/2012 comienza aludiendo al nuevo período recesivo que había experimentado la economía española a lo largo del año 2011 cuando, tras varios trimestres de leve recuperación, aquella se mostró intensamente vulnerable al deterioro de la zona euro y volvió a caer en recesión. Esta coyuntura obligó al Gobierno a diseñar una nueva política que pivotaba sobre dos ejes, a saber, "la consolidación fiscal y el impulso de las reformas estructurales". 
Para justificar la concurrencia del presupuesto de hecho habilitante, el Tribunal Constitucional remarca la urgencia de las medidas adoptadas en un contexto de recesión económica dando a entender que, en caso de haberse efectuado esta reforma $^{8}$, se podría en riesgo la propia existencia tanto del Sistema Nacional de Salud como del sistema de atención a la dependencia. Tampoco ve ninguna vulneración del art. 43 de la CE donde se regula el derecho a la protección de la salud, porque considera a éste como principio rector y no como derecho ${ }^{9}$, pudiendo por lo tanto regularse por Real DecretoLey del art. 86.1 de la CE.

Dejando de lado la problemática de las distintas normativas de las Comunidades Autónomas que bien han secundado, bien han recurrido dicha legislación ${ }^{10}$, me centraré en los siguientes aspectos:

- Definición del derecho a la protección de la salud, diferenciándolo, si procede, del derecho a la salud y del derecho a la asistencia sanitaria

- Naturaleza del derecho a la protección de la salud, como derecho social, norma programática o como derecho fundamental

- Consideraciones finales

\section{DEFINICIÓN DEL DERECHO A LA PROTECCIÓN DE LA SALUD}

El análisis del derecho a la protección de la salud plantea diferentes contextos en función del grado de desarrollo económico y social de los países. En efecto, hasta hace poco tiempo el estudio sobre el derecho a la salud venía motivado por los preocupantes informes que publica regularmente la Organización Mundial de la Salud en los que se pone de manifiesto las grandes desigualdades existentes entre países ricos y pobres. A partir de los años 2013 y 2014 empiezan a aparecer en España algunas referencias precisamente en

\footnotetext{
${ }^{8}$ No obstante, ha habido tres magistrados que han realizado dos votos particulares en los que manifiestan que es totalmente desproporcionado el excluir de la atención sanitaria a la población extranjera adulta en situación irregular y que además no se ha justificado la concurrencia del requisito habilitante de la "extrema y urgente necesidad" que requiere la utilización del Real Decreto-Ley.

${ }^{9}$ EI TC deja meridianamente claro que la medida no afecta al derecho a la protección a la salud, porque la pretendida universalidad de tal derecho, no puede confundirse con un derecho de gratuidad a las prestaciones y servicios sanitarios. Esta consecuencia no se deriva directamente de la Constitución sino que debe ser apreciada por el legislador en determinadas circunstancias. Estamos pues ante un derecho de configuración legal, de modo que el cambio de criterio por parte del legislador no afecta a la constitucionalidad de la medida.

${ }^{10}$ Véase A.M. MARCOS/F. PINTO, "El derecho a la salud y su universalidad en el contexto del derecho español", en SANZ BURGOS, R. (COORD.), Retos a la eficacia de los Derechos Humanos en España y en la Unión Europea, Comisión Nacional de Derechos Humanos de México, 2016, ISBN: 978-607-729-260-9, pp. 125-152; F. PINTO, "Consideraciones éticas y jurídicas acerca de la exclusión de la población inmigrante del derecho a la protección de la salud", en Dilemata, n. 5, 2015, pp. 103-133; A. SOLANES CORELLA, "La salud como derecho en España: reformas en un contexto de crisis económica", Derechos y libertades, número 31, época II, junio 2014, pp. 127-161.
} 
el momento en que se palpan en la sociedad $-\mathrm{y}$, especialmente, en determinados colectivos- las consecuencias de la crisis económica y de las medidas de austeridad que han supuesto un recorte presupuestario para el Estado del $13,7 \%$ en 2012 y del $16,2 \%$ en $2013^{11}$.

Se comienza a cuestionar la protección y garantía que el Estado otorga universalmente del derecho a la asistencia sanitaria. En los países más subdesarrollados, sin embargo, lo que está en juego es la vulneración del derecho a la salud, entendiendo la salud en el sentido más amplio de bienestar, incluyendo para su medición los niveles de pobreza, de desigualdad y las elevadas tasas de mortalidad y morbilidad a muy temprana edad ${ }^{12}$.

La mayoría de las Constituciones establecen las garantías del derecho a la protección de la salud que, en muchas ocasiones, se asimila al derecho a la asistencia sanitaria. Así se hace en la Constitución Española de 1978 que establece que la financiación del Sistema Nacional de Salud Pública corre a cargo de los presupuestos generales del Estado, la provisión de los servicios es eminentemente pública y gratuita en el momento del uso, garantizando de ese modo su universalidad ${ }^{13}$. Así fue también en las primeras Constituciones, como la de Querétaro en México en 1917 y la de Weimar en Alemania en 1919.

Como se desprende de estas pinceladas, se perfila así ya la diferencia de contenido entre el derecho a la salud, el derecho a la asistencia sanitaria y

\footnotetext{
${ }^{11}$ Vid. LEGIDO-QUIGLEY, H., URDANETA, E. GONZÁLEZ, A., LA PARRA, D., MUNTANER, C., ÁlVAREZ-DARDET, C., MARTÍN-MORENO, J.M. Y MCKEE, M., "Erosion of universal health coverage in Spain", The Lancet, 2013, núm. 382, vol. 382, vol. 9909, p. 1977.
}

\footnotetext{
${ }^{12}$ También es cierto que, si consultamos los últimos datos de la OCDE sobre nuestro país, las desigualdades y los niveles de malnutrición infantil están llegando a límites alarmantes que pueden influir no sólo en la salud actual de los niños/as sino, lo que agrava el problema, en su futuro. Datos de la OCDE sobre España: "la tasa de pobreza infantil subió en 3 puntos porcentuales a $21 \%$ (la media de la OCDE es de 13\%) y la tasa de pobreza entre los jóvenes registró un salto de 5 puntos". Véase en http://www.oecd.org/spain/OECDSocietyAtaGlance2014-Highlights-Spain.pdf (consultada el 10 de junio de 2015)

${ }^{13} \mathrm{Y}$ es que a lo largo de la breve historia del derecho a la salud han tenido lugar dos modelos de protección de la salud: uno, el modelo de Seguridad Social y otro, el modelo propio del Sistema Nacional de Salud. El primero se basa en las cotizaciones obligatorias de los trabajadores, constituyendo así un fondo de seguro que los cubre a ellos y a sus familias, restringiendo su protección a un sector de la sociedad y negando su universalidad. El segundo modelo parte de que la titularidad del derecho a la asistencia sanitaria corresponde a todos los habitantes del país. Al promulgarse la CE de 1978 comienza la complejidad pues se habla indistintamente de derecho a la asistencia sanitaria y de derecho a la salud pública debido a la indefinición de la naturaleza jurídica de las prestaciones sanitarias o, como también se ha señalado, a su híbrida naturaleza jurídica. La consecuencia es que poco a poco la asistencia sanitaria se fue desgajando progresivamente del sistema de Seguridad Social. Así se desarrolló la legislación sanitaria independientemente de la de Seguridad Social, constituyendo cuerpos normativos diferenciados. Se encomendó la gestión y organización de la asistencia sanitaria al Ministerio de Sanidad, distinto del de Trabajo. Las instituciones sanitarias del Sistema de Seguridad Social se integraron en el Sistema Nacional de Salud (SNS) y la financiación de la asistencia sanitaria, tras la Ley de Presupuestos de 1999, se asumió íntegramente por el Estado, suprimiéndose la referencia a las aportaciones procedentes de las cotizaciones sociales.
} 
derecho a la protección a la salud. El primero tiene que ver más con la definición de la salud que da la Organización Mundial de la Salud. "La salud es un estado de completo bienestar físico, mental y social, y no solamente la ausencia de afecciones o enfermedades"14, más relacionado con las condiciones económicas, sociales, culturales, de salubridad, de higiene, de alimentación y de educación y no sólo con cuestiones sanitarias. Mientras que el derecho a la asistencia sanitaria se circunscribe más a los aspectos clínicos y no tiene en cuenta los elementos socioeconómicos que pueden influir en tal derecho. Y el derecho a la protección a la salud se circunscribe al ámbito constitucional, precisamente porque no se puede establecer claramente un contenido material de lo que es salud ${ }^{15}$.

Sin embargo, la normativa internacional presenta una concepción amplia del derecho a la salud. La Carta fundacional de la Organización Mundial de la Salud en 1948 en el art. 25.1 de la Declaración Universal de los Derechos Humanos del mismo año y art. 12 del Pacto Internacional de los Derechos Económicos, Sociales y Culturales de 1966 y su desarrollo en la Observación General número $14^{16}$ comprenden este derecho como un derecho universal y en su sentido más totalizador e integrador de dimensiones diferentes a las estrictamente clínicas, conectado con otros derechos, como el de la educación, el de la vivienda, el del trabajo, etc ${ }^{17}$. Tiene gran importancia en la actualidad el Protocolo Facultativo del Pacto de Derechos Económicos, Sociales y Culturales, aprobado en Nueva York el 10 de diciembre de 2008, el cual entró en vigor en mayo de $2013^{18}$. Su relevancia radica en que este instrumento es fundamental en la evaluación y supervisión del respecto a tales derechos, entre ellos, el de la salud, por los Estados parte, permitiendo la presentación de quejas ante Naciones Unidas por vulneraciones y recordando la exigibilidad de estos derechos, aunque no deje de aumentar, incluso en nuestro país ${ }^{19}$.

\footnotetext{
${ }^{14}$ Preámbulo de la Constitución de la Organización Mundial de la Salud, que fue adoptada por la Conferencia Sanitaria Internacional, celebrada en Nueva York del 19 de junio al 22 de julio de 1946, firmada el 22 de julio de 1946 por los representantes de 61 Estados (Official Records of the World Health Organization, № 2, p. 100), y entró en vigor el 7 de abril de 1948. La definición no ha sido modificada desde 1948.
}

${ }^{15}$ Vid. C. LEMA AÑÓN, Salud, Justicia, Derechos. El derecho a la salud como derecho social, Madrid, Dykinson/ Instituto de Derechos Humanos Bartolomé de las Casas/ Universidad Carlos III de Madrid, 2009, pp. 69-70.

${ }^{16}$ A mayor abundamiento, podemos señalar: arts. 11, 13 y 19.2 de la Carta Social Europea; artículos 31.3 y 35 de la Carta de Derechos Fundamentales de la Unión Europea.

${ }^{17}$ La publicación de Informe Lalonde en los años 70 sobre los factores que se asociaban a la salud de los canadienses, marcó una nueva concepción de la misma, al enumerar los elementos que la afectaban: la biología humana, el entorno físico y social en el que las personas viven y trabajan, los estilos de vida, y los servicios sanitarios: http://www.hcsc.gc.ca/hcs-sss/medi-assur/faq-eng.php; Determinantes sociales de la Salud de la OMS: http://whqlibdoc.who.int/publications/2009/9789243563701 spa.pdf; véanse los videos sobre el derecho a la salud como derecho humano: http://www.determinantesdesalud.org/noticia/201310-31/videos-de-la-jornada-comprendiendo-el-derecho-humano-a-la-salud/

${ }^{18}$ En BOE, 25 de febrero de 2013.

${ }^{19}$ Ver el Informe del Defensor del Pueblo 2014, pp. 296-321. 
Además en esta comprensión del derecho a la salud como derecho humano hay que tomar en consideración los informes presentados ante el Comité de Derechos Económicos, Sociales y Culturales (DESC), así como las recomendaciones al Estado Parte en forma de observaciones finales. Este Comité ha interpretado este derecho a la salud como un derecho inclusivo, en el que incluye la atención sanitaria, además del acceso al agua potable, el suministro adecuado de alimentos en buen estado, una vivienda digna... Esta diferenciación ha llevado a hablar de una concepción reduccionista a los que asimilan el derecho a la salud a la asistencia sanitaria, entendiendo la concepción amplia del derecho a la salud como aquella que integra elementos socioeconómicos y no meramente la asistencia sanitaria ${ }^{20}$.

\section{NATURALEZA JURÍDICA DEL DERECHO A LA PROTECCIÓN A LA SALUD}

Desde el punto de vista jurídico el derecho a la salud implica una doble vertiente: negativa y positiva. Desde el punto de vista negativo, este derecho implica la abstención por parte de terceros para garantizar su respeto. Se considera el derecho a la salud como un derecho individual propiamente dicho. El Estado está obligado a impedir que se atente contra la integridad física de las personas, pero en principio, no obliga a procurar una asistencia sanitaria. Desde el punto de vista positivo, el reconocimiento del derecho a la asistencia sanitaria aparece recogido en las primeras Constituciones de principios del siglo XX. De ahí que la consideración del derecho social ${ }^{21}$ como derecho prestacional no deje de ser polémica, estos derechos son más bien de carácter complejo ${ }^{22}$.

\footnotetext{
${ }^{20}$ Precisamente el último Informe del SESPAS del 2016 (Sociedad española de Salud Pública y Administración Sanitaria) sostiene que "los determinantes sociales de la salud incluyen, además del sistema de salud, las circunstancias en que las personas nacen, crecen, viven, trabajan y envejecen, y explican gran parte de las desigualdades en salud. Un sistema de vigilancia de los determinantes sociales de la salud requiere una visión integral y social de la salud, en AAVV., "La vigilancia de los determinantes sociales de la salud", en Gaceta Sanitaria, 2016; 30, Supl. 1, pp. 38-44.

${ }^{21}$ Sobre la problemática del derecho a la salud como derecho social véase A.M. MARCOS/J. MÉNDEZ, "El derecho a la salud. perspectivas tras la crisis", en Revista de la Facultad de Derecho UNED, n. 19, (en prensa).

${ }^{22}$ Como afirman ABRAMOVICH Y COURTIS, la adscripción de un derecho al catálogo de los derechos civiles y políticos $\mathrm{o}$ al de los derechos sociales económicos y culturales, tiene más bien un valor heurístico, ordenatorio, clasificatorio, pero que una conceptualización más rigurosa basada sobre el carácter de las obligaciones que cada derecho genera llevaría a admitir un continuum de derechos, en el que el lugar de cada derecho esté determinado por el peso simbólico del componente de obligaciones positivas o negativas que lo caracterizan. Según estos autores, el derecho a la salud presenta dos perfiles delimitables: el primero, integrado por algunas obligaciones tendentes a evitar que la salud sea dañada, ya sea por conductas de terceros -Estado u otros particulares- (obligaciones negativas), o por factores controlables, tales como epidemias, prevenir enfermedades evitables, a través de campañas de vacunación- (obligaciones positivas). El segundo perfil es el de las obligaciones tendentes a asegurar la asistencia médica una vez producida la afectación a la salud denominadas habitualmente como "derecho a la asistencia sanitaria", cuyo contenido implica la complejísima
} 
Las distintas posiciones acerca de la naturaleza jurídica del derecho a la salud se podrían reagrupar en las siguientes:

Se trata de un derecho de prestación, es decir, son derechos subsidiarios, no son para todos, sino sólo para aquellos que los necesitan. Si es así se niega toda pretensión de universalidad ${ }^{23}$, debido a que están limitados a lo que sea "económicamente posible", ciñéndolos a una obligación positiva por parte de los poderes públicos para realizar determinadas actuaciones, de ahí además, que tengan menos posibilidades de protección jurisdiccional ${ }^{24}$.

O se puede considerar como una norma programática, un derecho de configuración legal que establecería simplemente las directivas de acción para el legislador ordinario, pero que no son accionables, que no son directamente exigibles $^{25}$. El legislador podrá adoptar sobre ellos cualquier tipo de decisión,

tarea de planificación y previsión de recursos presupuestarios necesarios para llevar a cabo la satisfacción de los requerimientos de salud correspondientes a toda la población. Vid. V. ABRAMOVICH / CH. COURTIS, Los derechos sociales como derechos exigibles, Madrid, Trotta, 2004, p. 22

23 Esta posición además no advierte de que el derecho a la salud además contiene otras dimensiones que no son prestacionales. Si bien se puede entender que los derechos sociales son prestacionales y por lo tanto para grupos diferenciados y que no son para todos, no es así en el caso del derecho a la protección de la salud que sí es para todos. ¿Quién se sale de este marco de protección? ¿Hay alguien que no necesite que se le proteja su salud? Se trata de un derecho de ciudadanía y no como una prestación que depende de un aseguramiento aunque este sea público. Sobre todo, si tenemos en cuenta que nuestro Sistema Nacional de Salud se financia vía impositiva, tanto directa como indirecta, luego todos estamos ya incluidos y, en mi opinión, se puede hablar de universalidad del derecho.

${ }^{24}$ Véase M.J. AÑÓN ROIG, "Derechos sociales: cuestiones de legalidad y de legitimidad", en Anales de la Cátedra de Francisco Suárez, 2010, 44, p. 21.

${ }^{25}$ Son las normas impropias porque en sí mismas no llevan implícita la coercibilidad, es decir, la posibilidad de que el Estado las haga efectivas aquí y ahora de un modo coactivo y tampoco pueden alegarse ante los órganos jurisdiccionales. Se trata entonces de principios informadores o "rectores de la política social" como dice nuestra Constitución, pero que no se trata de derechos subjetivos. En efecto, el Capítulo III del Título I comprende un conjunto heterogéneo de normas cuya estructura, contenido y eficacia presenta importantes diferencias. Así, por ejemplo, no se puede equiparar el objetivo estatal de "salvaguardia de los derechos económicos y sociales de los trabajadores españoles en el extranjero" (artículo $42 \mathrm{CE}$ ) con la garantía institucional de la Seguridad Social (artículo 41 CE) o con la necesidad de "garantizar, mediante pensiones adecuadas y periódicamente actualizadas, la suficiencia económica de los ciudadanos durante la tercera edad" (artículo $50 \mathrm{CE}$ ). De igual manera, el derecho a la salud presenta unos rasgos constitucionales diferentes por cuanto su tutela está directamente relacionada con el mantenimiento del estado psicofísico del ciudadano y, en última instancia, de su vida. Desde este punto de vista, la obligación del Estado de tutelar este derecho es mucho más intensa que en otros principios rectores. En efecto, la tutela de la salud individual y, a su vez, de la pública, tiene una importancia esencial pues el mantenimiento de unas mínimas condiciones de vida es condición necesaria para el ejercicio de cualquier otro derecho fundamental. Véase también PINTO, "Consideraciones éticas...", 2015, pp. 103-133: Por tal motivo, la doctrina ha sostenido que el derecho a la salud es un "principio rector subjetivado" que goza de fuerza expansiva debido a sus conexiones directas e indirectas con otros derechos fundamentales de máxima relevancia como el derecho a la vida, a la integridad física o a la intimidad. En este sentido, el principio rector proyecta otras perspectivas que se pueden encuadrar en la dimensión objetiva de los derechos fundamentales. Este sería el caso de los 
incluida la de vaciarlos de contenido, limitarlos injustificadamente 0 sencillamente una total inacción ${ }^{26}$.

Se ha considerado también como necesidad. El derecho a la protección de la salud se configura como un derecho básico del individuo porque protege un bien primario, una necesidad básica, cuya privación le impedirá ser dueño de sí mismo, desarrollarse como persona y como ciudadano. La idea de necesidad básica constituiría de ese modo un parámetro para valorar los obstáculos económicos y sociales reales para el ejercicio de la libertad individual y permite reflexionar y planificar los medios para su remoción ${ }^{27}$. Otros autores consideran que es un derecho social propiamente dicho. Los derechos sociales se caracterizan por involucrar un espectro de obligaciones estatales. Desde una perspectiva clásica se entiende que su carácter social proviene de dos planos: uno, el subjetivo, el derecho social proviene del derecho de cada ciudadano a participar en los beneficios de la vida asociada, el cual se refleja en derechos específicos a determinadas prestaciones, directas o indirectas, de parte de los poderes públicos. El segundo, el objetivo que es el conjunto de normas a través de las cuales el Estado lleva a la práctica su función equilibradora y moderadora de las desigualdades sociales. En cualquier caso, son derechos que exigen prestaciones del Estado; se trata de un imperativo ético por parte del Estado, para satisfacer necesidades básicas de los individuos. El derecho de asistencia sanitaria no se puede considerar única y exclusivamente de la persona, pues tiene un componente social, en la prevención y defensa de la salud pública en sí misma. Algunos sostienen que no se puede considerar universal, precisamente por la imposibilidad de declarar los derechos sociales (incluyendo el derecho a la protección a la salud entre ellos) como derechos universales porque están directamente vinculados a las políticas sociales y económicas de los gobiernos, no permitiendo su igual atribución a todos los hombres. Por otro lado, algunos alegan que si predicáramos de los derechos sociales su universalidad se produciría una contradicción interna, pues esa universalización mantendría inalteradas las desigualdades reales, diferencias cuya corrección constituye la justificación de la existencia de los derechos ${ }^{28}$.

llamados "deberes de protección" que recaen sobre los poderes públicos frente a las lesiones y amenazas contra los bienes jurídicos tutelados por los derechos fundamentales.

${ }^{26}$ Véase AÑÓN ROIG, “Derechos sociales...”, 2010, p. 21.

${ }^{27}$ No obstante, el concepto de necesidad no deja de ser problemático. Así, por ejemplo, algunos autores desde la teoría liberal pretenden reducir la necesidad a los deseos o caprichos individuales. Las necesidades de las que se habla aquí en la protección al derecho a la salud no pueden estar sujetas a estados de ánimo que pueden ser volubles, sino que requieren una objetividad, cual es la enfermedad o el riesgo de caer en ella. Las necesidades de las que aquí se habla no son ni preferencias ni deseos ni están sujetas a los dictados del interés personal. Las necesidades que fundamentan los derechos sociales son hechos objetivos, mensurables y constatables por cuanto son elementos fundamentales de la relación del individuo con el medio que le rodea y sus condiciones de vida. Véase J.M. MARTíNEZ DE PISÓN, "El derecho a la salud: un derecho social esencial", en Derechos y Libertades, año 10, $n$. 14, 2006, p. 120; J. DE LUCAS/M.J. AÑÓN, "Necesidades, razones y derechos", en Doxa, 1990, n. 7, pp. 55-81.

${ }^{28}$ Véase B. DE CASTRO, "Estado social y crisis de los derechos económicos, sociales y culturales", en Derechos y libertades, año 3, n. 6, 1998, p. 22. 


\section{CONSIDERACIONES FINALES}

La reforma del año 2012 ha supuesto un giro radical a la normativa sobre asistencia sanitaria cuya consecuencia más palpable ha sido la expulsión de un grupo de personas de la cobertura pública, universal y gratuita del Sistema Nacional de Salud. Y ello ha supuesto directamente un cambio en la naturaleza del derecho a la protección de la salud, afectando a su núcleo esencial, a saber, su titularidad. Es indispensable distinguir entre titularidad y ejercicio. La reforma del legislador no puede suponer la privación de la titularidad del derecho a un determinado grupo de personas por carecer de residencia legal pues ello supone, en definitiva, una quiebra de la vocacional universal que preside la protección de la salud. En este sentido, debemos recordar que el artículo $43 \mathrm{CE}$ no exige el requisito de la nacionalidad lo que, a su vez, se reitera en los Tratados internacionales suscritos por España en esta materia. La universalidad está relacionada con la titularidad del derecho, no con su ejercicio.

Aunque en principio está incluido en la Constitución Española como principio rector de la política social, ello no obsta para incluirlo en el marco de los derechos subjetivos exigibles, pues afecta directamente a un derecho fundamental, por la vía de la afectación directa al art. 15 de la CE e incluye la obligación positiva de los poderes públicos de velar por la concreción de esos principios y su garantía de un modo universal. Y es que una de las finalidades de los servicios de salud es garantizar la salud de toda la ciudadanía, pero no como una prestación del Estado a los ciudadanos sino que hay que poner de manifiesto que quien paga no es el Estado, sino que son los ciudadanos que contribuyen a que ellos mismos $u$ otros ciudadanos reciban esa cobertura prestacional. El paraguas asistencial se debe ampliar hasta cubrir a toda la población, incluidos los que todavía no los necesitan, pero que está presente como posibilidad en el horizonte vital de todos los ciudadanos.

Como tampoco se puede asumir como argumento para el incumplimiento del derecho a la protección de la salud, la ausencia de recursos económicos. El mismo Comité de Derechos Económicos, Sociales y Culturales de la ONU ha sostenido que para "que cada Estado parte pueda atribuir su falta de cumplimiento de las obligaciones mínimas por falta de recursos disponibles, debe demostrar que ha realizado todo esfuerzo para satisfacer, con carácter prioritario, estas obligaciones mínimas. Además no basta con que los Estados demuestren la existencia de recursos limitados, tienen que evidenciar un uso eficaz, equitativo y oportuno de esos recursos" ${ }^{\prime 2}$.

\footnotetext{
${ }^{29}$ Los partidos políticos que comenzaron a gobernar en las CCAA después de las elecciones del 24 de mayo de 2015 priorizaron entre sus propuestas la sanidad pública o aspectos incluidos en otros derechos sociales. Véase por ejemplo: Andalucía prepara un anteproyecto para evitar copagos en Sanidad, http://www.actasanitaria.com/andalucia-aprueba-unanteproyecto-de-ley-que-descarta-copagos/ (consultada el 24 de junio de 2015).
} 
Actualmente, el modelo más propio del Estado social hoy es el modelo del Sistema Nacional de Salud en el que el derecho a la protección de la salud se extiende a toda la población, financiándose por los presupuestos generales del Estado. Es decir, lo que surgió como un derecho de grupo se extendió a toda la población y nos da muestra del carácter progresivo de los derechos sociales y de la imposibilidad de su regresividad ${ }^{30}$. Y aunque evidentemente haya derechos sociales para grupos específicos como pueden ser las mujeres, los niños, los emigrantes, ello no obsta para que se pueda predicar la titularidad universal de los derechos sociales. En unos casos se extenderá a todos los seres humanos y en otros se extenderá a un grupo especificado.

Además, actualmente no se puede entender el derecho a la protección a la salud como un derecho de grupo, porque ¿quiénes constituirían ese grupo, todos los pobres? ¿Todos los excluidos? ¿Todos los inmigrantes? Estaríamos alejándonos del paradigma de la universalidad para incluirnos en el paradigma de la beneficencia (de nuevo regresividad), vulnerando todos Tratados internacionales en los que aparece este derecho recogido, aparte de estigmatizar a todos aquellos que por sus especiales circunstancias no puedan satisfacer dicho derecho por sus propios medios.

Y es que en el campo de los derechos sociales como el derecho a la protección a la salud es muy importante no sólo la forma en que se distribuye, sino también en cómo se produce ese bien. Es decir, esos bienes han de ser producidos socialmente, sino queremos que adquieran la forma de mercancías. Es necesaria la desmercantilización del derecho a la asistencia sanitaria. La salud o la educación no pueden ser intercambiables, tampoco podemos fomentar la idea de ganadores y competidores y tampoco la de ganadores y perdedores. Se considera que la forma lógica de obtener dicho producto (asistencia sanitaria en nuestro caso) es en el mercado y subsidiariamente entraría el Estado.

El derecho a la asistencia sanitaria, su protección y garantía está, tan vinculado al derecho a la vida y a la integridad física y psíquica, que se debe predicar del mismo su universalidad, porque se puede considerar un derecho fundamental y no meramente de una norma programática ${ }^{31}$. El argumento

\footnotetext{
${ }^{30}$ Véase M.J. AÑóN, ¿Hay límites a la regresividad de los derechos sociales?", en Derechos y Libertades, 2016, pp. 58-91, en el que la autora sostiene la tesis de acuerdo con la cual "los retrocesos o la reversibilidad de los derechos sociales son decisiones normativas limitadas fundamentalmente por dos expedientes, garantías o salvaguardas. El primero es la posibilidad de determinar un contenido esencial para los derechos sociales. El segundo radica en situar el peso de la justificación de la decisión en la identificación de la legitimidad del fin de la norma".
}

${ }^{31}$ En este sentido, AÑÓN ROIG, "Derechos sociales...", 2010, pp. 15-41: "es posible una teoría de los derechos fundamentales que integre los derechos sociales; no existen, en este sentido, razones dogmáticas o teóricas de peso que justifiquen su configuración, interpretación y protección diferenciada respecto de otros derechos, con los que, antes bien, comparten elementos teóricos y estructurales". Y, por otro lado, no es igual el derecho a la salud, por afectar directamente a la vida, que el derecho a una vivienda, o que el derecho al matrimonio, o que el derecho a la huelga y a la sindicación, todos ellos derechos sociales. 
positivista de que está situado en el marco de los principios rectores de política social no puede ahogar la vinculación real que este derecho tiene con el derecho a la vida y a la integridad física y psíquica. Esta es precisamente la posición que el Tribunal Constitucional, por otra parte, venía manteniendo hasta ahora ${ }^{32}$ y que en este momento ha modificado con la reciente STC 139/2016, de 21 de julio, acerca de los recortes en el acceso a la asistencia sanitaria. El Tribunal Constitucional se había pronunciado al respecto en el ATC 239/2012, de 12 de diciembre, que levantaba la suspensión que pesaba sobre el Decreto del País Vasco 114/2012, de 26 de junio, que establecía la titularidad universal del derecho a la salud al extenderlo a las personas en caso de "no tener acceso a un sistema de protección sanitaria pública por cualquier otro título" (artículo 2.3, letra c). El Tribunal Constitucional expone que el caso analizado plantea un conflicto, por un lado, el beneficio económico y por el otro el interés general del derecho a la salud consagrado en el art. 43 CE. Aquí el Alto Tribunal sostiene que es necesario proteger este derecho recordando que "todos los poderes públicos de garantizar a todos los ciudadanos el derecho a la protección de la salud, cuya tutela les corresponde y ha de ser articulada a través de medidas preventivas y de las prestaciones y servicios necesarios". Asimismo, el Tribunal Constitucional reitera la doctrina que establece la vinculación entre el principio rector del artículo $43 \mathrm{CE}$ y el derecho a la vida y a la integridad física del artículo $15 \mathrm{CE}$ lo que permite concluir que "los intereses generales y públicos, vinculados a la promoción y garantía del derecho a la salud, son intereses asociados a la defensa de bienes constitucionales particularmente sensibles".

El análisis del Tribunal Constitucional se ha limitado a un "control externo" o, si se quiere, formal que radica en la comprobación de una situación de extraordinaria y urgente necesidad para reformar tanto el sistema de sanidad como el de dependencia, ambos pilares de un modélico Estado del Bienestar. Si bien es cierto que el juicio político está vedado al Tribunal Constitucional, lo cierto es que asume el planteamiento del Gobierno central y considera que la situación de crisis económica justificó la adopción urgente de medidas que implicaban, en definitiva, un reducción de la cobertura ofrecida por el Estado del bienestar a personas especialmente vulnerables.

En definitiva, consideramos el derecho a la protección de la salud como un derecho fundamental con la misma protección de estos, por su intrínseca e indisoluble unidad al derecho a la vida y a la integridad física y psíquica, además de que es un requisito previo para poder disfrutar del resto de los derechos $^{33}$. Y es que algunos de los Estados miembros de la UE han decidido

32 Sobre las sentencias del Tribunal Constitucional en las que asimila la protección a la salud
del art. 43 CE al derecho a la vida y a la integridad física y psíquica, véase: GUERRA
VAQUERO, A.Y., "La protección de la salud y del derecho a la integridad física en tiempos de
crisis", en Revista de la Facultad de Derecho de la UNED, 2015, n. 16, pp. 1265-1292.
${ }^{33}$ Sostenemos aquí la teoría de la indivisibilidad e interdependencia de los derechos humanos,
así lo afirma la Declaración de Viena en 1993: "todos los derechos humanos son universales,
indivisibles e interdependientes e interrelacionados. La comunidad internacional debe tratar
globalmente los derechos humanos de una forma justa e igual, en pie de igualdad y con igual
énfasis". Los países están obligados no sólo a la protección y garantía de los derechos civiles y 
excluir a una gran parte de sus propias poblaciones de sus sistemas sanitarios, vulnerando así los principales valores sobre los que se ha construido la UE que es la solidaridad y el respeto a los derechos humanos ${ }^{34}$.

\section{BIBLIOGRAFÍA UTILIZADA}

AAVV., "La vigilancia de los determinantes sociales de la salud", en Gaceta Sanitaria, 2016; 30, Supl. 1, pp. 38-44.

ABRAMOVICH, V./COURTIS, CH., Los derechos sociales como derechos exigibles, Madrid, Trotta, 2004.

AÑÓN ROIG, M.J., "Derechos sociales: cuestiones de legalidad y de legitimidad”, en Anales de la Cátedra de Francisco Suárez, 2010, pp. 15-41.

- ¿Hay límites a la regresividad de los derechos sociales?", en Derechos y Libertades, 2016, pp. 58-91

ARANA GARCÍA, E., "Uso y abuso del Decreto-Ley", Revista de Administración Pública, núm. 191, mayo-agosto 2013, pp. 337-365.

BLASCO LAHOZ, J.F., "Modificaciones en materia de asistencia sanitaria consecuencia del RD-L 26/2012, de 20 de abril", Revista de Información Laboral, núm. 11/2012.

DE CASTRO, B., "Estado social y crisis de los derechos económicos, sociales y culturales", en Derechos y libertades, año 3, n. 6, 1998, pp. 51-72.

DE LUCAS, J./AÑÓN, M.J., "Necesidades, razones y derechos", en Doxa, 1990, n. 7, pp. 55-81.

GUERRA VAQUERO, A.Y., "La protección de la salud y del derecho a la integridad física en tiempos de crisis", en Revista de la Facultad de Derecho de la UNED, 2015, n. 16, pp. 1265-1292.

LEGIDO-QUIGLEY, H., URDANETA, E. GONZÁLEZ, A., LA PARRA, D., MUNTANER, C., ÁlVAREZ-DARDET, C., MARTÍN-MORENO, J.M. Y MCKEE,

políticos, sino también de los derechos sociales, algo que todavía es un reto para Europa: en el último Informe de Médicos del Mundo presentado en noviembre de 2016, "Informe del Observatorio 2016, El acceso a la atención sanitaria de las personas con vulnerabilidad en salud, en Bruselas se denuncia la falta de cobertura sanitaria para refugiados e inmigrantes: "el $68 \%$ de las personas que llegaron a los dispositivos de Médicos del Mundo no tenía cobertura de salud (incluidas las mujeres embarazada), y solicita que "todos los países europeos deben garantizar por lo menos un acceso completo a la plena cobertura sanitaria para cualquiera que viva en esos países. Eso ahorraría mucho dinero, mucho dolor y mucho sufrimiento", en https://www.medicosdelmundo.org/index.php/mod.documentos/mem.descargar/fichero.docume ntos Resumen ejecutivo informe europeo 2016 a59d6af0\%232E\%23pdf

${ }^{34}$ Sin embargo, en otros países como Grecia la situación estratégica del país en la acogida de personas refugiadas ha provocado la promulgación de la Ley 4368/2016, de 20 de febrero, que concedió el libre acceso a la atención sanitaria a pacientes no asegurados y a grupos vulnerables. La ley del 18 de diciembre de 2015 en Luxemburgo aumentó el acceso a la atención sanitaria para las personas solicitantes de asilo y refugiadas, pero no para las migrantes en situación administrativa irregular; y una reforma de 2015 en Rumanía amplió el paquete básico de servicios de salud para quienes carecieran de seguro médico. 
M., "Erosion of universal health coverage in Spain", The Lancet, 2013, núm. 382, vol. 382, vol. 9909, p. 1977.

LEMA AÑÓN, C., Salud, Justicia, Derechos. El derecho a la salud como derecho social, Madrid, Dykinson/ Instituto de Derechos Humanos Bartolomé de las Casas/ Universidad Carlos III de Madrid, 2009.

MARCOS, A.M./MÉNDEZ, A.M., "El derecho a la salud. Perspectivas tras la crisis", en Revista de la Facultad de Derecho UNED, n. 19, (en prensa).

MARCOS, A.M./PINTO, F., "El derecho a la salud y su universalidad en el contexto del derecho español", en SANZ BURGOS, R. (COORD.), Retos a la eficacia de los Derechos Humanos en España y en la Unión Europea, Comisión Nacional de Derechos Humanos de México, 2016, ISBN: 978-607729-260-9, pp. 125-152.

MARTÍNEZ DE PISÓN, J.M., "El derecho a la salud: un derecho social esencial", en Derechos y Libertades, año 10, n. 14, 2006, pp. 129-150.

PINTO, F., "Consideraciones éticas y jurídicas acerca de la exclusión de la población inmigrante del derecho a la protección de la salud", en Dilemata, n. 5, 2015, pp. 103-133.

SOLANES CORELLA, A., "La salud como derecho en España: reformas en un contexto de crisis económica", Derechos y libertades, número 31, época II, junio 2014, pp. 127-161. 